haemorrhage. Continuing coma for a period of 24 hours after adequate resuscitation was a grave prognostic sign and in this series clearly separates those surviving with handicap from those surviving intact. The cause of the coma is unclear. A study of cortical blood flow during this period would be of considerable interest since blood entering the subarachnoid space by the foramina of the 4th ventricle may cause arterial spasm and a secondary depression of cortical function. A report by Cooke et al. ${ }^{7}$ on apparent cerebral blood flow in the newborn, mentions observations on 2 very low birthweight babies with 'massive' IVH. In neither infant was apparent cerebral blood flow detectable after the onset of clinical signs suggesting IVH, but details of the neurological state were not given. It is possible that a closer study of babies after IVH may provide a basis for more rational treatment designed, not only to improve survival, but also to reduce morbidity.

\section{References}

1 Papile L-A, Burstein J, Burstein R, Koffler H. Incidence and evolution of subependymal and intraventricular hemorrhage: a study of infants with birth weights less than 1500 g. J Pediatr 1978; 92 : 529-34.

2 Ahmann P A, Lazzara A, Dykes F D, Brann A W, Schwartz J F. Intraventricular hemorrhage in the highrisk preterm infant: incidence and outcome. Ann Neurol 1980; 7: 118-24.

3 Volpe J. Intracranial hemorrhage in the newborn: current understanding and dilemmas. Neurology 1979; 29: 632-5.

4 Amiel C. Hémorrages cérébrales intraventriculares chez le prématuré. 2 partie. Les elements du diagnostic clinique. Biol Neonatorum 1965; 75: 57-75.

5 Krishnamoorthy K S, Shannon D C, DeLong G R, Todres I D, Davis $K R$. Neurologic sequelae in the survivors of neonatal intraventricular hemorrhage. Pediatrics 1979; 64: 233-7.

6 Deonna T, Payot M, Probst A, Prod'hom L S. Neonatal intracranial hemorrhage in premature infants. Pediatrics 1975; 56: 1056-64.

7 Cooke R W I, Rolfe P, Howat P. Apparent cerebral blood flow in newborns with respiratory disease. Dev Med Child Neurol 1979; 21: 154-60.

Correspondence to Dr R O Robinson, Newcomen Centre, Guy's Hospital, St Thomas Street, London SE1 9RT.

Received 9 July 1980

\title{
Trimeprazine and respiratory depression
}

\author{
NICHOLAS P MANN \\ City Hospital, Nottingham
}

SUMMARY Respiratory depression is described in two siblings after oral administration of less than the maximum recommended dose of trimeprazine tartrate.

Trimeprazine tartrate is commonly used in paediatric practice for premedication, sedation, and relief of pruritis. ${ }^{1}$ Acute poisoning may be associated with central nervous system depression and hypothermia. ${ }^{2}$ Extrapyramidal symptoms, elation or depression of mood and, rarely, agranulocytosis may follow recommended dosage. Two cases of severe respiratory depression in siblings are described after normal dosage of trimeprazine tartrate.

\section{Case reports}

Case 1. A 3-month-old, $6 \cdot 3-\mathrm{kg}$ boy, who had no history of respiratory illness, was admitted to hospital for repair of bilateral cleft lip and palate.
This was carried out successfully and there were no postoperative problems. Nasal packs had been removed and there was no evidence of any airway obstruction. Forty-eight hours postoperatively he was given an oral dose of $15 \mathrm{mg}$ trimeprazine tartrate $(2.4 \mathrm{mg} / \mathrm{kg})$ for night sedation. He became drowsy after administration of the drug and had a respiratory arrest $5 \frac{1}{2}$ hours later, requiring resuscitation using facial oxygen and skin stimulation for 3 to 4 minutes. A further respiratory arrest occurred 9 hours after the first, again responding to similar measures. Chest $x$-ray films showed no abnormality and no reason for the respiratory arrest was found. He made a full recovery without neurological or respiratory sequelae.

Case 2. The 3-year-old sister of Case 1, and weighing $12 \mathrm{~kg}$, had a minor surgical procedure for repair of a small fistula of the palate. She had had two operations previously for repair of her cleft lip and palate without any postoperative problems. $35 \mathrm{mg}(2 \cdot 9$ 
$\mathrm{mg} / \mathrm{kg}$ ) of oral trimeprazine tartrate was given 5 days postoperatively before the sutures were removed. Four hours later she became drowsy, examination showing her to be deeply unconscious with no response to painful stimuli. Her respiratory rate was slow at 10 /minute with very shallow respiration. Air entry was poor to both sides of the chest, but there was no cyanosis. Neurological examination showed dilated pupils which were equal in size, as well as a divergent squint. Her gag reflex was intact and no other focal signs or manifestations of raised intracranial pressure were evident; blood pressure was $120 / 70 \mathrm{mmHg}$, and Dextrostix recordings were normal. Her condition slowly improved during the next 6 hours and she made a full recovery.

\section{Discussion}

Trimeprazine has pharmacological actions intermediate to promethazine and chlorpromazine, thus having marked antihistamine effects as well as central nervous system actions similar to chlorpromazine. Antihistamine drugs in toxic doses produce complex central nervous system effects, ${ }^{3}$ which can lead to respiratory depression. Respiratory depression has not been reported after recommended doses of trimeprazine tartrate, and it is of interest that both siblings responded in a similar manner.

Kahn and Blum. ${ }^{4}$ suggested that trimeprazine tartrate in normal dosage $(1 \mathrm{mg} / \mathrm{kg}$ per day) was the possible cause of death in 7 infants with sudden infant death syndrome. All infants tended to be sleepy and they suggested that the central nervous system action caused prolonged sleep apnoea leading to death.

In both these children there was no antecedent history of respiratory illness or drug sensitivity, and no other drugs were administered concurrently. The maximum recommended dose of trimeprazine is up to $5 \mathrm{mg} / \mathrm{kg}$ orally, ${ }^{2}$ and each patient was given a dose considerably smaller than this. An idiosyncratic response to trimeprazine must be suggested in these 2 children leading to respiratory and central nervous system depression.

I thank the Drug Information Service at Nottingham City Hospital, and Mr Malcolm Deane, Consultant Plastic Surgeon, for permission to publish this report, and Dr A D Milner for advice.

\section{References}

1 Wood-Smith F G, Vickers M D, Stewart H C. Drugs in anaesthetic practice. London: Butterworth, 1973: 82-3.

2 Wade A, ed. Martindale. The extra pharmacopoeia, twenty-seventh edition. London: Pharmaceutical Press, 1977: 1307-8.

3 Dreisbach R H. Handbook of poisoning: diagnosis and treatment. Los Altos, California: Lange Medical Publications, 1977: 320-1.

4 Kahn A, Blum D. Letter: Possible role of phenothiazines in sudden infant death. Lancet 1979; ii: 364-5.

Correspondence to Dr N P Mann, Children's Department, University Hospital, Queen's Medical Centre, Nottingham NG7 2UH.

Received 2 July 1980

\title{
Henoch-Schönlein nephritis: long-term prognosis of unselected patients
}

\author{
O KOSKIMIES, SEVGI MIR, J RAPOLA, AND J VILSKA \\ Children's Hospital, University of Helsinki
}

\begin{abstract}
SUMMARY Progressive glomerulonephritis is the most serious feature of Henoch-Schönlein syndrome. In a series of 141 children with Henoch-Schönlein purpura $39(28 \%)$ had abnormal urinary sediment for a duration of more than one month. This subgroup was followed up for 3.0 to 13.8 (mean 7.2) years. One child progressed to renal failure and 2 developed chronic glomerular disease. In this series most of the patients with Henoch-Schönlein syndrome and nephritis had a good prognosis.
\end{abstract}

The long-term prognosis of children with HenochSchönlein (HS) syndrome and nephritis is not yet clear. ${ }^{1}$ One child in 4 with HS nephritis being treated in a renal unit in the UK was found to have chronic renal disease, or to be in renal failure after a follow-up of a mean of 10 years. ${ }^{2}$ In our experience the long-term (mean $7 \cdot 2$ years) prognosis of a less selected patient population with HS nephritis is more favourable.

Patients, methods, and results

In 1964-76 a total of 141 patients with HS syndrome 